\title{
Isolation of dental stem cell-enriched populations from continuously growing mouse incisors
}

\section{Balic, A.}

Humana press

2019

Balic , A 2019 , Isolation of dental stem cell-enriched populations from continuously growing mouse incisors . in P Papagerakis (ed.), Odontogenesis : Methods and Protocols . Methods in Molecular Biology , vol. 1922 , Humana press , pp. 29-37 . https://doi.org/10.1007/978-1-4939-9012-2_4

http://hdl.handle.net/10138/327589

https://doi.org/10.1007/978-1-4939-9012-2_4

acceptedVersion

Downloaded from Helda, University of Helsinki institutional repository.

This is an electronic reprint of the original article.

This reprint may differ from the original in pagination and typographic detail.

Please cite the original version. 


\title{
Isolation of dental stem cell enriched populations from continuously growing mouse incisors
}

\author{
Anamaria Balic \\ Research Program in Developmental Biology, Institute of Biotechnology, University of \\ Helsinki, Finland
}

\section{Summary}

\section{Introduction}

In recent years major effort has been made toward generating dental tissues in vitro, for the tooth regeneration purposes. The major setback is the lack of appropriate cell source that would be feasible for clinical use and our inability to induce odontogenic potential in these cells. Continuous growth of the rodent incisor is enabled by epithelial and mesenchymal stem cells (ESCs and MSCs) which unceasingly replenish enamel and dentin, respectively, that wear by persistent animal gnawing. Therefore, this tooth is a perfect source of stem cells to study their fates and differentiation in vivo, as well as to obtain them for further molecular and cellular analyses in vitro.

ESCs reside in a morphologically distinct cervical loops located at the proximal end of the incisor and are identified as label-retaining cells expressing Sox2, Bmi1, Oct4/3, Lgr5 and Yap (Balic and Thesleff 2015; Harada et al. 1999; Li et al. 2011; Suomalainen and Thesleff 2010). Lineage tracing studies have provided evidence that ESCs contribute to all epithelial lineages of the tooth in vivo (Biehs et al. 2013; Juuri et al. 2012; Seidel et al. 2010). Extensive studies on mouse incisor have unraveled some of the molecular regulatory networks which govern in vivo maintenance and differentiation of ESCs into various epithelial cell lineages. However, in vitro manipulation of ESCs has shown little progress, mainly due to lack of appropriate protocol to successfully isolate, culture, expand and differentiate ESCs in vitro without using the co-culture system. 
In contrast, in vitro odontoblast differentiation and dentin production have been analyzed extensively in the past decades using dental pulp tissue obtained from various species and mainly from teeth which seize to grow. These teeth are abundant in the progenitor cells and contain very low number of MSCs that are involved in reparative dentinogenesis (Balic et al. 2010). Meanwhile, in the mouse incisor MSCs continuously contribute to odontoblast lineage and tooth growth. The MSCS are mainly recruited into dental pulp from the neurovascular bundle, a network of blood vessels and mandibular nerve that penetrates incisor dental pulp and brings various MSC populations, including nerveassociated glial cells and pericytes (Feng et al. 2011; Kaukua et al. 2014; Zhao et al. 2014). Some of the recruited cells reside in the mesenchyme spanning the lingual and labial cervical loops as Thy $1+($ CD90+) and label retaining cells (Kaukua et al. 2014).

In recent years transgenic mice carrying GFP coding sequences under the control of cellspecific regulatory elements have emerged as a powerful tool for developmental and lineage studies of the specific cell populations, including stem cells. Easily accessible FACS sorting enables easy and relatively fast isolation of the cells labeled by the fluorescent protein. In this chapter we describe the isolation of the Sox2-GFP+ cell population that is highly enriched in ESCs. Isolated cells can be used for various types of analyses, including in vitro culture, single cell-related analyses, etc. Furthermore, we will describe ways to obtain populations enriched in the incisor MSCs using FACS sorting of antibody labeled cells.

\section{Materials}

\subsection{Reagents:}

-PBS

-Hank's balanced salt solution (Sigma, cat. no. H 4034)

- Collagenase P (Roche, CAT\# 11213857001)

- Dispase (Sigma, D4693)

- Pancreatin (Sigma, P-3292) 
- Trypsin (Difco, 215240)

$-\mathrm{NaCl}$

$\bullet \mathrm{KCl}$

- $\mathrm{NaH}_{2} \mathrm{PO}_{4}+\mathrm{H}_{2} \mathrm{O}$

- Glucose

- $\mathrm{NaHCO}_{3}$

-Sodium Acetate

- Calcium Acetate

- Fetal calf/bovine serum

- HEPES

- Propidium lodide

-DMEM

\subsection{Media and solutions:}

- Dissecting media: 1xHBSS; 10mM HEPES, pH7.2

- Dispase solution: prepare Dispase stock solution (activity $50 \mathrm{U} / \mathrm{ml}$ ) in Dispase buffer (10mM NaOAC, $5 \mathrm{mM} \mathrm{CaOAc}$, pH7.4). Can be stored at $+4^{\circ} \mathrm{C}$ for a month.

- Pancreatin, 10x stock solution: $25 \mathrm{~g} / \mathrm{L}$ Pancreatin, $8,5 \mathrm{~g} / \mathrm{L} \mathrm{NaCl}$ in milipore water, $\mathrm{pH} 7.0$, filter sterilize. Store in $1 \mathrm{ml}$ aliquots at $-20^{\circ} \mathrm{C}$.

- Pancreatin-Trypsin solution: $1 \mathrm{ml}$ of Pancreatin stock solution, $0,225 \mathrm{~g}$ of Trypsin, dissolve in $6 \mathrm{ml}$ of Tyrode solution. Store in $1 \mathrm{ml}$ aliquots at $-20^{\circ} \mathrm{C}$.

- Recovery Media: 10\% Fetal Bovine (Calf) Serum in DMEM

- Collagenase solution: $0.5-3 \mathrm{U} / \mathrm{ml}$ Collagenase P in PBS. 
- Sorting media: 1xHBSS; 2\% Fetal Bovine Serum; 10mM HEPES, pH7.2 and $1 \mu \mathrm{g} / \mathrm{ml}$ Propidium lodide

- Tyrode solution $\left(\mathrm{Ca}^{2+}, \mathrm{Mg}^{2+}\right.$ free): $8 \mathrm{~g} / \mathrm{L}$ of $\mathrm{NaCl} ; 0,2 \mathrm{~g} / \mathrm{L}$ of $\mathrm{KCl} ; 0,005 \mathrm{~g} / \mathrm{L}$ of $\mathrm{NaH}_{2} \mathrm{PO}_{4}+\mathrm{H}_{2} \mathrm{O} ; 1 \mathrm{~g} / \mathrm{L}$ of Glucose and $1 \mathrm{~g} / \mathrm{L}$ of $\mathrm{NaHCO}_{3}$. Filter sterilize and store at $+4^{\circ} \mathrm{C}$.

\section{Methods}

Sacrifice the mice following the established and approved Animal Care protocols and decapitate them. Separate the mandible from the rest of the head and place it to a Petri dish containing PBS. Continue until all the mandibles are isolated. Split the mandible to two by cutting through cartilage symphysis and clean the soft tissue as much as possible. Note that mandibles obtained from P10 and older mice are mineralized and easy to clean, while those obtained from younger pups are softer and more fragile (Figure 1).

Separate the coronoid process from alveolar bone using tweezers. The bone breaks easily when using tweezers to grip the coronoid part in the close proximity to the third molar and breaking it by pushing toward buccal side of the mandible. Most often the coronoid process of the mandible will break as a plate exposing the entire proximal end of the incisor, as well as the neurovascular bundle. The following text describes how to separately isolate populations of interest. Just small modifications of the protocol are required to enable isolation of all of them from the same mandible.

\subsection{Isolation of the incisor ESCs}

1) Push the apical end of the incisor away from the bone and dissect the most proximal part containing cervical loop (Figure 1D and E).

2) There are at least three possible ways to obtain cervical loop, one is mechanical separation and other two involve enzymatic separation using different enzyme(s):

a) Mechanical separation is best in cases where time for isolation is limited. If performed with great care, the contamination with the adjacent mesenchyme is minimal. Use fine tweezers to gently pull the cervical loop away from the 
dental pulp mesenchyme. Once the cervical loop is obtained dissect out as much of the differentiating epithelial tissue (preameloblasts and ameloblast layers, stratum intermedium, etc.). Collect the cleaned cervical loops in PBS.

b) Enzymatic separation can be performed using Dispase enzymatic solution or Pancreatin-Trypsin. Always use glas dishes.

When using Dispase, prepare a working solution by diluting the stock solution in the Optimem to obtain final activity of $2-2,5 \mathrm{U} / \mathrm{ml}$. Incubate the apical ends of the incisor with Dispase on room temperature for $20 \mathrm{~min}-1 \mathrm{~h}$, with gentle rocking. Check every $20 \mathrm{~min}$ if the epithelium is separating. Use fine tweezers or 28G needle to separate the cervical loops. Transfer the cervical loops to the new Petri dish with the clean PBS to stop the enzyme activity.

Pancreatin-Trypsin treatment takes $1-8$ minutes at $+37^{\circ} \mathrm{C}$ to effectively separate epithelium from the mesenchyme. Collect the separated cervical loops into a glass dish containing enzymatic solution and swirl occasionally at $+37^{\circ} \mathrm{C}$. When you observe that cervical loops are detaching from the mesenchyme, transfer them into Recovery Media containing DMEM and 10\% Fetal Bovine (or Calf) Serum. The presence of serum stops the enzyme activity and also allows the tissue to recover. Keep the tissue in the Recovery Media for up to an hour and then use fine tweezers or $28 \mathrm{G}$ needles to separate the cervical loops completely from the mesenchyme of the dental pulp.

Pancreatin-Trypsin enzymatic dispersion is time wise a long procedure, but it ensures complete separation of the cervical loops with no mesenchymal cell contamination.

3) Place the isolated and cleaned cervical loops in Collagenase solution (activity $3 \mathrm{U} / \mathrm{ml}$ ) and incubate at $37^{\circ} \mathrm{C}$ with gentle rocking for $15-45$ minutes.

If the cervical loops were separated mechanically they will require longer time to enzymatically disperse to single cell solution.

4) Stop the enzymatic dispersion by addition of the Fetal Bovine (or Calf) Serum. 5$10 \%$ Fetal Bovine Serum is sufficient to inactivate the enzymes. Gently mix the samples and spin at 1,500-3,000 RPM for $10 \mathrm{~min}$. at $+4^{\circ} \mathrm{C}$. 
5) Mechanically break loose tissue fragments using trituration method to ensure optimal yield of cells.

6) Strain the cells through $70 \mu \mathrm{m}$ strainer and count them using dyes such as Trypan Blue to exclude dead cells.

7) Centrifuge the cells at $1,000-1,500 \mathrm{RPM}$ for $10 \mathrm{~min}$. at $+4^{\circ} \mathrm{C}$ and reconstitute the cell pellet in Sorting media to reach a cell density between $0,5 \times 10^{6}$ and $1 \times 10^{6} \mathrm{celll} / \mathrm{ml}$ to ensure that cells do not adhere together until sorting is completed.

For the proper FACS sorting it is recommended to have a negative control, as well as the control for each of the fluorophores used.

To ensure the optimal survival of the cells during sorting, media with higher concentration of the fetal calf (bovine) serum can be used. However, cells adherence can increase and repeated filtering might be required.

8) Proceed with sorting according to the regulations dictated by your FACS Core Facility and collect the cells in media determined by the type of the study they will be used for.

\subsection{Isolation of cell populations enriched in MSCs from the neurovascular bundle}

After breaking the coronoid bone of the mandible and exposing the entire proximal end of the incisor (Figure 1B), use tweezers to push the apical end of the incisor away from the bone. The neurovascular bundle, which can be observed capping the apical end of the incisor, is easily removed (Figure 1B and $\mathrm{C}$ ).

1) Collect the isolated bundles into Collagenase solution $(0.5 \mathrm{U} / \mathrm{ml})$ and incubate at $37^{\circ} \mathrm{C}$ with gentle rocking for no more than 15 minutes.

2) Use gentle trituration method to further disperse the bundles and to ensure optimal yield of cells.

3) Strain the tissue through $40 \mu \mathrm{m}$ strainer and stop the enzymatic dispersion by addition of the Fetal Bovine (or Calf) Serum. 5-10\% Fetal Bovine Serum is sufficient to inactivate the enzyme.

4) Gently mix the samples and spin at $800-1,200$ RPM for $10 \mathrm{~min}$. at $+4^{\circ} \mathrm{C}$. 
Spinning the sample at low speed minimizes the amount of dispersed nerve tissue that is a byproduct of enzymatic dispersion and can interfere with the survival of the cells.

5) Reconstitute the cell pellet in $100-500 \mu \mathrm{l}$ PBS at cell density of $0,5-1 \times 10^{6} \mathrm{cells} / \mathrm{ml}$ and proceed with the antibody labeling described in the following section.

\subsection{Isolation of MSCs from the incisor dental pulp}

After breaking the coronoid process of the mandible and exposing the entire proximal end of the incisor, use tweezers to push the apical end of the incisor away from the bone (Figure 1)and dissect the most proximal part containing cervical loop. Dental pulp mesenchyme spanning the loops is the location of the Thy1+, Gli1+ and Axin2+, slowcycling label-retaining MSCs.

1) Remove cervical loops as described in section 3.1. The best way is the mechanical separation by gentle pulling of the labial cervical loop away from the dental pulp mesenchyme. The lingual cervical loop is smaller and can be pinched off with fine tweezers. Mechanical removal of cervical loops is sometimes followed by the removal of the small number of mesenchymal cells directly adjacent to the cervical loops. However, these are most likely cells already committed to odontoblast lineage and not the focus of this protocol.

6) Collect the cleaned apical mesenchyme in a $15 \mathrm{ml}$ tube containing Collagenase $P$ solution $(1.5 \mathrm{U} / \mathrm{ml})$ for enzymatic cell dispersion. Pulp tissue dispersion is performed at $37^{\circ} \mathrm{C}$ with gentle rocking for no more than 45 minutes. After the initial 15 min., the solution becomes cloudy due to active tissue dissociation and extracellular matrix breakdown, indicative of optimal enzymatic activity necessary for successful cell harvest.

7) Enzymatic dispersion is stopped by addition of the Fetal Bovine (or Calf) Serum. 5$10 \%$ Fetal Bovine Serum is sufficient to inactivate the enzymes. Gently mix the samples and spin at 1,500-3,000 RPM for $10 \mathrm{~min}$. at $+4^{\circ} \mathrm{C}$.

8) Mechanically break loose tissue fragments using trituration method to ensure optimal yield of cells. 
9) Strain the cells through $70 \mu \mathrm{m}$ strainer and count them using dyes such as Trypan Blue to exclude dead cells.

10) Centrifuge the cells at $1,500-3,000$ RPM for $10 \mathrm{~min}$. at $+4^{\circ} \mathrm{C}$ and reconstitute the cell pellet in $100-500 \mu \mathrm{l}$ of PBS at cell density of $0,5-1 \times 10^{6}$ cells $/ \mathrm{ml}$.

11) Proceed with antibody labeling.

Most of the antibodies used for the FACS or flow cytometry analyses are already conjugated. However, there are occasionally those that require secondary antibody labeling. The following protocol describes the procedure for the use of conjugated antibodies.

12) To the tube with cells add primary antibody in a correct dilution that has been predetermined.

13) Gently mix and place the tube on ice for $45 \mathrm{~min}$ in dark.

14) Add fresh PBS and spin the cells at 1,200 RPM for $5 \mathrm{~min}$.

15) Discard the PBS and repeat the wash at least once more.

16) Resuspend the cells in sorting media and proceed with sorting according to the regulations dictated by your FACS Core Facility.

\section{Notes}

\subsection{Strategy for FACS sorting}

Most often FACS sorting is performed by appropriately trained personnel who will ensure that the cell sorter is optimized and that it is sorting accurately. Select the appropriate nozzle dependent on the type of cells that are sorted.

To determine an accurate fluorescence gating scheme, control samples are necessary to distinguish between the true and false positive and/or negative cells. These controls include

A. the full negative sample obtained from the same tissue from the nontransgenic animal using the same protocol and placed in the sorting media with no Propidium lodide $(\mathrm{PI})$. 
B. control for fluorofuore used: sample of the same tissue obtained from nontransgenic animal and placed in the sorting media with no PI.

C. Control for PI: sample of the same tissue obtained from non-transgenic animal using the same protocol and placed in the sorting media with $\mathrm{PI}$.

Following the FACS sorting, a re-analysis of the sorted samples reassures the purity of the sorted populations that should not be below $97.5 \%$.

\section{REFERENCES:}

Balic A, Aguila HL, Caimano MJ, Francone VP, Mina M. 2010. Characterization of stem and progenitor cells in the dental pulp of erupted and unerupted murine molars. Bone. 46(6):1639-1651.

Balic A, Thesleff I. 2015. Tissue interactions regulating tooth development and renewal. Curr Top Dev Biol. 115:157-186.

Biehs B, Hu JK, Strauli NB, Sangiorgi E, Jung H, Heber RP, Ho S, Goodwin AF, Dasen JS, Capecchi MR et al. 2013. Bmil represses ink4a/arf and hox genes to regulate stem cells in the rodent incisor. Nat Cell Biol. 15(7):846-852.

Feng J, Mantesso A, De Bari C, Nishiyama A, Sharpe PT. 2011. Dual origin of mesenchymal stem cells contributing to organ growth and repair. Proc Natl Acad Sci U S A. 108(16):6503-6508.

Harada H, Kettunen P, Jung HS, Mustonen T, Wang YA, Thesleff I. 1999. Localization of putative stem cells in dental epithelium and their association with notch and fgf signaling. J Cell Biol. 147(1):105-120.

Juuri E, Saito K, Ahtiainen L, Seidel K, Tummers M, Hochedlinger K, Klein OD, Thesleff I, Michon F. 2012. Sox2+ stem cells contribute to all epithelial lineages of the tooth via sfrp5+ progenitors. Dev Cell. 23(2):317-328.

Kaukua N, Shahidi MK, Konstantinidou C, Dyachuk V, Kaucka M, Furlan A, An Z, Wang L, Hultman I, Ahrlund-Richter L et al. 2014. Glial origin of mesenchymal stem cells in a tooth model system. Nature. 513(7519):551-554.

Li L, Kwon HJ, Harada H, Ohshima H, Cho SW, Jung HS. 2011. Expression patterns of abcg2, bmi-1, oct-3/4, and yap in the developing mouse incisor. Gene expression patterns : GEP. 11(3-4):163-170.

Seidel K, Ahn CP, Lyons D, Nee A, Ting K, Brownell I, Cao T, Carano RA, Curran T, Schober $\mathrm{M}$ et al. 2010. Hedgehog signaling regulates the generation of ameloblast progenitors in the continuously growing mouse incisor. Development. 137(22):3753-3761.

Suomalainen M, Thesleff I. 2010. Patterns of wnt pathway activity in the mouse incisor indicate absence of wnt/beta-catenin signaling in the epithelial stem cells. Developmental dynamics : an official publication of the American Association of Anatomists. 239(1):364-372 . 
Zhao H, Feng J, Seidel K, Shi S, Klein O, Sharpe P, Chai Y. 2014. Secretion of shh by a neurovascular bundle niche supports mesenchymal stem cell homeostasis in the adult mouse incisor. Cell Stem Cell. 14(2):160-173. 


\section{Figures}

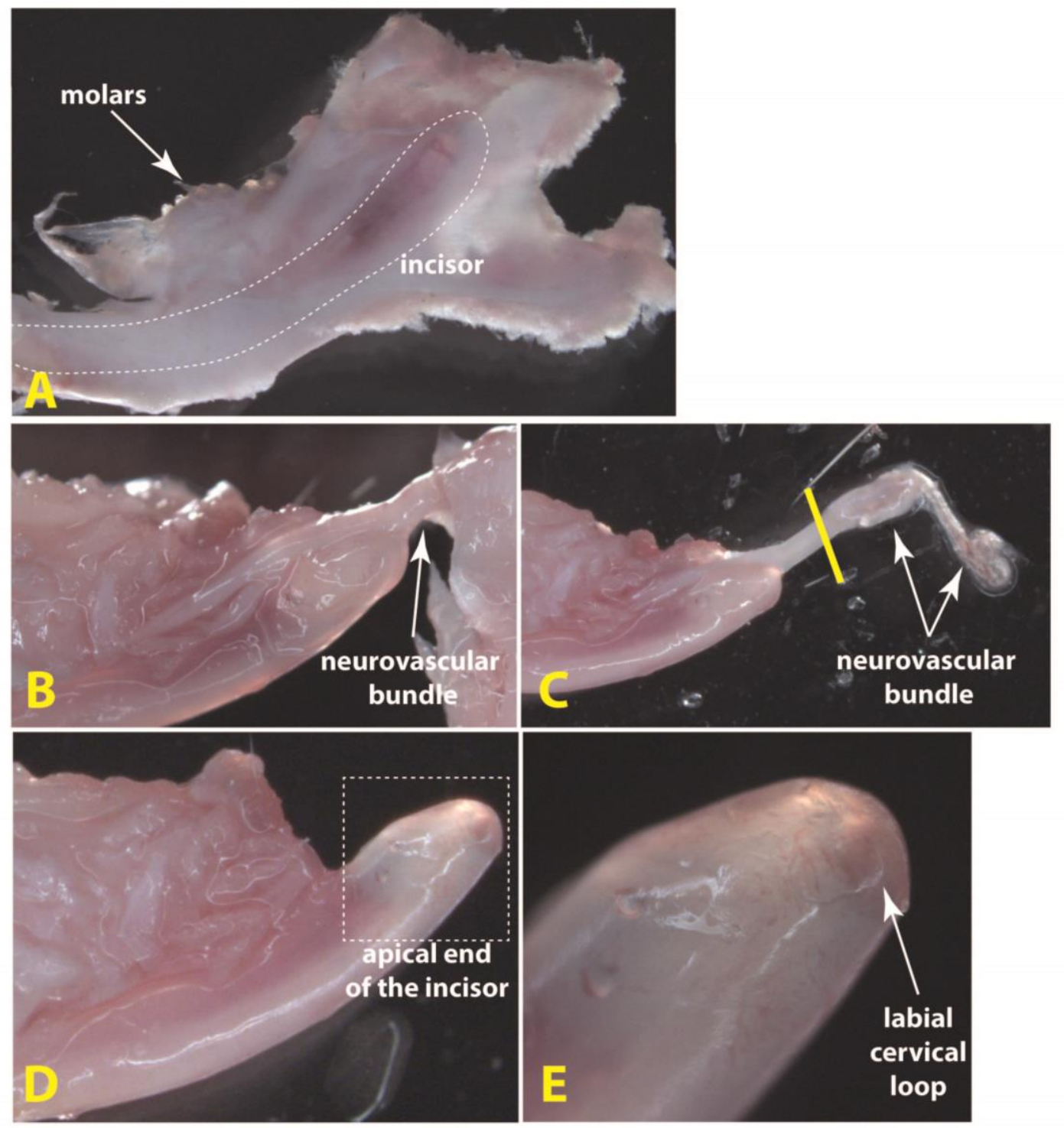

Figure 1. Dissection of the neurovascular bundle and the apical end of the incisor from murine mandible. Mandible of the 8 weeks old mouse has been isolated and cleaned from the surrounding tissue $(A)$. Breaking the coronoidal process exposed the neurovascular bundle (white arrow) and the remaining of mandibular nerve ( $\mathrm{n}$. mandibularis) that is part of the neurovascular bundle (B). Neurovascular bundle is gently pulled away and cut as indicated by yellow line (C). The apical end of the incisor is clearly visible (D) and labial cervical loop can be observed (E). 